certain of these changes occurred to a lesser degree in stress involution. The stress-involuted thymuses in our study showed the well-known change of cortical atrophy (Hammar, 1921), cystic Hassall's corpuscles, which have been observed in the involuted thymuses of guinea-pigs given cortisone or $x$-irradiation (Blau, 1965), and an increased percentage area of epithelial cell aggregates, these also being regarded by Lattes (1962) as associated with stress. The nature of these epithelial aggregates remains uncertain. Their appearances may be due simply to loss of lymphocytes with condensation of reticuloepithelial cells, or they may represent hyperplasia of reticuloepithelial cells, perhaps as a reaction to stress. The fact that these epithelial aggregates are seen to some degree in stressed thymuses makes it unlikely that they have any unique relation to systemic lupus erythematosus.

The finding that certain of the thymic changes in svistemic lupus erythematosus are an exaggeration, albeit gross, of those present in stress involution is in keeping with the prolonged and often debilitating course of the disease, the long terminal stages, and intense treatment with "thymolytic" drugs such as corticosteroids and mercaptopurines. However, we would emphasize that our series contained three surgically resected thymuses, two of which were from patients who had not received "thymolytic" drugs, yet both showed changes as pronounced as others in the series. On the other hand, the greatly increased numbers of plasma cells in the thymus in systemic lupus erythematosus and the presence of germinal centres in the medulla in two of the cases could not be accounted for by stress involution, and point rather to an immune (probably autoimmune) reaction within the thymus (Goldstein, 1966).

C.un interpretation is that the thymus in systemic lupus erythematosus is a target organ. There is histological evidence of extreme stress involution and of an autoimmune reaction which could augment changes usually associated with stress involution.

\section{Summary}

Structural changes in the thymus were assessed by a quantitative method in 13 patients with systemic lupus erythematosus and in two groups of control cases representing minimal stress (94 cases) and stress involution (104 cases).

The changes of stress involution included reduction of cortex, epithelial cell aggregates in the medulla, and cystic Hassall's corpuscles. In systemic lupus erythematosus there was pronounced lymphocytic depletion resulting in complete cortical atrophy and disorganization of the medulla. A large proportion of the medulla (mean 36\%) was occupied by epithelial cell aggregates, and there was a high proportion (89\%) of cystic Hassall's corpuscles; moreover, there were greatly increased numbers of plasma cells, and germinal centres were present in two cases.

Our interpretation is that the thymus in systemic lupus erythematosus is a target organ. There is histological evidence of extreme stress involution and of an autoimmune reaction which could augment changes usually associated with stress involution.

We are grateful to Dr. J. D. Hicks, pathologist to the Royal Melbourne Hospital, Dr. J. McNamara, pathologist to the Coroner's Court, Melbourne, and Dr. A. Williams, pathologist to the Royal Children's Hospital, Melbourne, for enabling us to obtain thymuses for our control series. Dr. Grover M. Hutchins kindly referred three thymuses from patients with systemic lupus erythematosus (Cases 7, 8, and 9, Table II) from the Johns Hopkins Hospital, Baltimore. Mrs. Louise Stewart and Mr. A. Bargerbos provided excellent technical assistance.

\section{REFERENCES}

Blau, J. N. (1965). Nature (Lond.), 208, 564.

Boyd, E. (1932). Amer. F. Dis. Child., 43, 1162

Burnet, F. M. (1962). Aust. Ann. Med., 11, 79.

- and Mackay, I. R. (1965). F. Path. Bact., 89, 263.

Goldstein, G. (1966). Aust. F. exp. Biol. med. Sci., 44, 695.

- (1967). Clin. exp. Immunol., 2, 103.

- (19) Mckay. I. R. (1965). Aust. 7. exp. Biol. med. Sci., 43, 38

Ham and Mackay, 1.12 . Endocrinology, $5,543$.

Hammar, J. A. (1921). Endocrinology, (1964). Bull. fohns Hopk. Hosp. 115,355 .

$115,355$.
Lattes, R. (1962). Cancer (Philad.), 15, 1224.

Mackay, I. R., and de Gail, P. (1963). Lancet, 2, 667

- Masel, M., and Burnet, F. M. (1964). Aust. Ann. Med., 13, 5 - and Smalley, M. (1966). Clin. exp. Immunol., 1, 129.
Nineteen liver transplants have been performed in large white pigs (20-30 kilograms) under halothane anaesthesia via an endotracheal tube. Donor and recipient were littermates

* Department of Surgery, University of Cambridge. in some cases; in others there was no relationship. The surgical technique was similar to that of Moore et al. and of Starzl et al.; however, minor modifications of the shunting procedure and arterial anastomosis were incorporated in certain experiments. In the first 11 operations, during the interruption of flow through the portal vein and inferior vena cava, blood from these two systems was shunted via catheters in the splenic and left femoral veins respectively joined to a $T$ tube which connected to another catheter introduced into the left internal jugular vein. In the twelf th experiment two shunts were usedone from the splenic vein to the left jugular vein, the other from the right renal vein to the right jugular vein. The right kidney was removed. In the remaining seven operations catheters were inserted direct into the cut ends of the portal vein and inferior vena cava and connected respectively to the left and right jugular veins. In all cases the animals were heparinized while the shunts were open and the heparin was reversed with protamine at the end of the procedure. In the 
operations where the splenic vein was used, a splenectomy was performed.

In the first six experiments the donor liver was removed with the hepatic artery, coeliac artery, and a length of abdominal aorta which was anastomosed end-to-side to the abdominal aorta of the recipient. It was felt that this large vessel, with all but one of its outlets ligated, was haemodynamically unsatisfactory and its dissection added considerably to the time of the donor operation. Therefore in the subsequent experiments the coeliac artery with a Carrel patch of aorta was removed in continuity with the hepatic. In experiments $7-11,13$, and 14 the coeliac artery of the donor was anastomosed to the side of the coeliac artery of the recipient. In experiment 12 the coeliac artery of the donor was anastomosed to the end of the right renal artery after the kidney had been removed. In the remaining five operations the coeliac artery was anastomosed with a Carrel patch direct to the abdominal aorta close to the origin of the coeliac artery of the recipient. In experiments 15 and 16 the coeliac artery was brought behind the stomach to the left side of the aorta. This resulted in tension, so in subsequent operations the coeliac artery was anastomosed direct to the right side of the aorta by the shortest route.

The anaesthetized donor pig was cooled to $33^{\circ} \mathrm{C}$. in a bath of iced water prior to surgery. When the liver dissection was completed the animal was exsanguinated via the aorta. The blood was collected in ACD bags and used for transfusion into the recipient. The blood was neither grouped nor cross-matched. The liver was perfused via the portal vein with 2 litres of Ringer/lactate solution at $4^{\circ} \mathrm{C}$. with a perfusion pressure of 1 metre of saline. During the operation and postoperatively, in addition to blood transfused from the donor, the recipient pig was given sodium bicarbonate and dextrose solution through an intravenous catheter in a suitable neck vein. One gramme of chloramphenicol was given intravenously during the operation and 1 megaunit of penicillin intramuscularly. The animals that survived the operation were given an ad lib. diet of commercial pig-food and water; they did not receive immunosuppressive agents. Venous samples of blood were taken for biochemical and haematological investigation at irregular intervals after operation. Postmortem examination was carried out on the animals. The thoracic and abdominal cavities were examined and sections of liver, lymph nodes, spleen in nonsplenectomized animals, lungs, stomach, small intestine, and kidneys were examined histologically.

\section{Results}

The results are summarized in the Table. There were six operative deaths. The causes are shown in the Table, with the exception of experiment 10, where the cause of death was undetermined. This animal died at the end of the operation while the operative incision was being sutured. Five died within the first 36 hours. One of these animals had peritonitis and clot in the hepatic artery and donor section of aorta. In the other experiments the cause of death was not determined, but was presumed to be liver failure. In one of these cases the liver had been preserved for four and a half hours in ice before transplantation. Two animals died at three days. One had a thrombosed hepatic artery and two intussusceptions, the other had obstructive jaundice following inadvertent ligation of the cystic duct together with the common bile duct.

Five animals lived between 7 and 16 days. In each of these there was microscopical evidence of rejection. This consisted of focal necrosis of liver cells and round-cell infiltration of the portal triads. One of these animals died from obstructive jaundice due to ligation of the cystic duct with the common bile duct, another of multiple sepsis after necrosis of the anterior wall of the stomach due to embolization of the left gastric artery. The other three developed a syndrome of wasting and very severe anaemia due to bleeding from the gastrointestinal tract with melaena. The source of the haemorrhage was not determined with certainty in any of these animals, but it was thought to be from multiple superficial erosions of the gastric and duodenal mucosa.

The remaining animal lived with a transplant from its littermate for seven months after operation. Though it was extremely robust and ate well, it did not gain weight to the same extent as control animals and it grew more hair on its skin than normal. This animal died suddenly from intestinal obstruction due to adhesions. The liver parenchyma was remarkably normal at postmortem examination. There was a minimal increase of fibrous tissue in the portal triads with a light infiltration of mononuclear cells.

The chemical and haematological examinations of the blood were related to the clinical assessment and histological findings. Thus clinical jaundice was associated with a raised serum bilirubin, liver necrosis with raised S.G.O.T., S.G.P.T. and alkaline phosphatase, and melaena and pallor with low haemoglobin.

\section{Discussion and Conclusions}

In common with the French and Bristol workers, we have found the pig an extremely satisfactory experimental animal -for orthotopic liver transplantation experiments. The pig withstands the surgery well and the liver appears to be rejected more slowly in the pig than in the dog, allowing more time

Orthotopic Liver Transplantation in the Pig

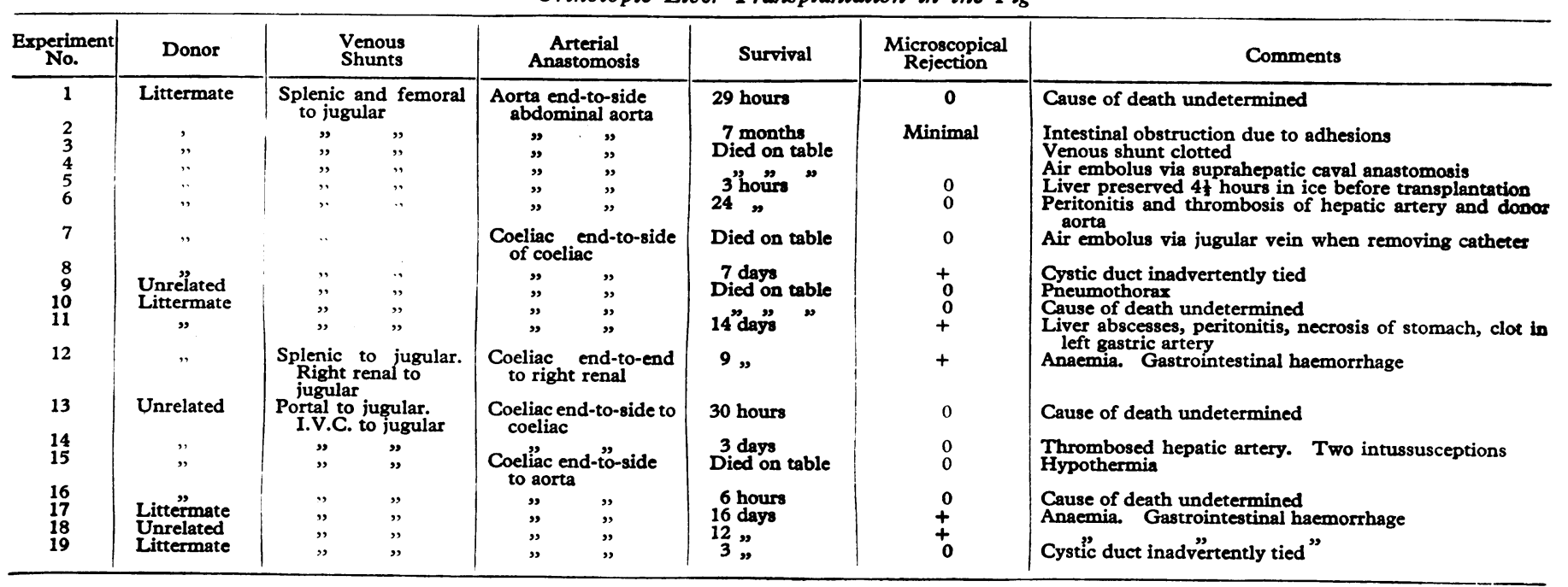


for study of the animals, without necessity for immunosuppressive therapy. Halothane anaesthesia was effective ; the animals were kept fairly light throughout the procedure and were usually on their feet within a few hours of the operation. In those animals surviving more than a week classical liver failure did not appear to be the cause of death. However, the gastrointestinal haemorrhage may well have been due to inadequate liver function, though the exact mechanism has not been determined. It will certainly be of interest to study the gastric secretion, metabolism of histamine, the haemodynamics of portal venous flow, and the composition and distribution of bile in these animals. Peptic ulceration is a common complication of orthotopic liver transplantation in dogs. The Bristol workers have also observed gastrointestinal haemorrhage in pigs with orthotopic liver transplants and have demonstrated superficial mucosal erosions in the cardiac portion of the stomach. A perforated duodenal ulcer was the cause of death of one of the pigs in the French experiments.

In our pig herd skin grafts are rejected aggressively when the donor and recipient are unrelated (Binns, 1967), and even in littermates rejection is the rule, though skin grafts may persist up to three weeks. The mechanism of acceptance of an orthotopic liver transplant in our longest-surviving animal at seven months and a similar animal of the Bristol group at nine months (Peacock, personal communication) has not been determined. Though splenectomy has little effect on the survival time of transplanted tissue in most species that have been studied, it is possible that splenectomy in pigs with liver transplants may influence the outcome of the transplant.
This early experience encourages us to pursue further studies with liver transplantation in the pig.

\section{Summary}

Our preliminary experience with orthotopic liver transplantation in the pig is reported. Of the 19 operations performed 13 animals survived the procedure and six lived for a week or more. One pig with an orthotopic liver transplant from a littermate lived for seven months after operation without any immunosuppressive therapy and died from intestinal obstruction, with minimal microscopical evidence of liver damage.

We wish to thank Dr. Marek Zakiewicz for the help he has given with the anaesthesia of the pigs, and we acknowledge the excellent technical assistance that we have received from the staff of the Department of Surgery, University of Cambridge, and the Agricultural Research Council at Babraham. We are most grateful to Dr. R. D. Keynes for providing facilities at the A.R.C., Babraham.

\section{REFERENCES}

Binns, R. M. (1967). Nature (Lond.), 214, 179 Cordier, G., Garnier, H., and Clot, J.-P. (1966). Mém. Acad. Chir., 92, 799.

Garnier, H., et al. (1965). C.R. Acad. Sci. Paris, 260, 5621.

Moore, F. D., et al. (1960). Ann. Surg., 152, 374.

Staryl, T. E, Kaup H. A., jun., Brock, D. R., Lazarus, R. E., and , ., Kaup, 1960 ., Surg., Gynec, Obstet., 111, 733.

Terblanche, J., et al. (1967). Brit. J. Surg., 54, 231.

\title{
Lead Absorption in Children
}

\author{
NEIL GORDON,* M.D., F.R.C.P.ED., M.R.C.P. ; E. KING,* R. I. MACKAY,* M.B., CH.B., M.R.C.P., D.C.H.
}

The possibility of a causal relationship between lead absorption and mental retardation has been suggested by Moncrieff et al. (1964). They claimed that lead was a greater factor in producing mental retardation than previously thought and that the estimation of lead in the blood was the only certain way of demonstrating excessive exposure to lead. It was believed that a blood lead level of over $36 \mu \mathrm{g} . / 100 \mathrm{ml}$. was an indication of intoxication, because 80 normal children were examined and all but two had levels below this. This problem has been studied in Manchester and Salford, a densely populated area undergoing an extensive slum-clearance programme.

\section{Clinical Material}

In order to try to establish the possible role of lead poisoning the blood lead levels of 147 mentally retarded children aged 5 months to 18 years were examined. They were either attending training centres under the authority of the Salford Mental Health Department or had been admitted for investigation to the wards of the Royal Manchester Children's Hospital and the paediatric department at Hope Hospital, Salford. A control group of 73 children aged 1 to 19 years were taken from those admitted to the wards of these hospitals for known conditions that precluded the possibility of lead poisoning. There are obvious

- The Service for the Handicapped Child, Royal Manchester Children's Hospital and the Nuffield Department of Occupational Health, Manchester University. disadvantages of cheosing such children suffering from a variety of medical and surgical diseases, but there was no possibility of collecting a sufficiently large number in normal health. The controls were drawn from the same population as the mentally handicapped children but were not matched for race or social class. The children with Down's syndrome were analysed separately from the other mentally handicapped children to see if the blood leads of a group with a known aetiology differed significantly from the rest. The blood lead level of $50 \mu \mathrm{g} . /$ $100 \mathrm{ml}$. was chosen as the possible dividing line between normality and abnormality on the previous experience of the Nuffield Department of Occupational Healih in the area of Manchester and Salford. The blood lead estimations were repeated on 14 of the children with levels of over $50 \mu \mathrm{g} . / 100 \mathrm{ml}$.

Of the whole group of mentally handicapped children there were 121 with blood lead levels below $50 \mu \mathrm{g}$. $/ 100 \mathrm{ml}$. and 26 above this figure. Among these were 24 mongol children, and the comparable values for them were 19 and 5 respectively. The control group showed 60 children with blood lead levels below and 13 with levels above $50 \mu \mathrm{g} . / 100 \mathrm{ml}$. The 14 children whose blood lead levels were re-cxamined included eight of the group of mentally handicapped of uncertain cause, two of the mongols, and four of the controls. In 10 of them the blood lead level had returned to a value below $50 \mu \mathrm{g}$./ $100 \mathrm{ml}$. One of each of the first two groups and two of the controls still had a level of above $50 \mu \mathrm{g} . / 100 \mathrm{ml}$. on the second examination. 